\title{
Usefulness of tissue inhibitor of metalloproteinase 1 as a predictor of sustained remission in patients with antineutrophil cytoplasmic antibody- associated vasculitis
}

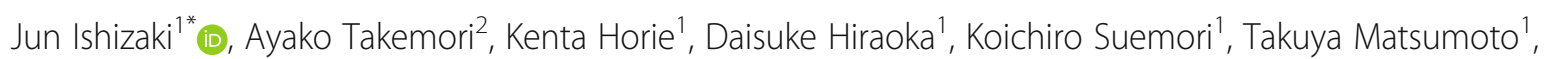
Ken-ei Sada ${ }^{3}$, Koichi Amano ${ }^{4}$, Masayoshi Harigai ${ }^{5}$, Yoshihiro Arimura ${ }^{6,7}$, Hirofumi Makino ${ }^{8}$, Katsuto Takenaka', Nobuaki Takemori ${ }^{2}$, Hitoshi Hasegawa ${ }^{1 *}$ and for the Research Committee of Intractable Vasculitis Syndrome and the Research Committee of Intractable Renal Disease of the Ministry of Health, Labour and Welfare of Japan

\begin{abstract}
Background: We previously identified tissue inhibitor of metalloproteinase 1 (TIMP-1) as a biomarker of disease activity that distinguished mildly or highly active antineutrophil cytoplasmic antibody (ANCA)-associated vasculitis (AAV) from remission 6 months after the initiation of remission-induction therapy. In the present study, we investigated whether TIMP-1 is clinically useful as a predictor of relapse and sustained remission in AAV patients with microscopic polyangiitis (MPA) and granulomatosis with polyangiitis (GPA) during maintenance therapy.
\end{abstract}

Methods: The relationship between serum TIMP-1 levels and clinical outcomes in AAV patients receiving maintenance therapy was assessed using the follow-up data of a Japanese large-cohort study (the RemIT-JAV-RPGN study) and data collected from AAV patients on maintenance therapy in our hospital (the MAAV-EU study).

Results: In the RemIT-JAV RPGN study, serum levels of TIMP-1 were significantly higher in mildly active AAV patients with MPA and GPA 6 months after the initiation of remission-induction therapy than in patients in remission. Regarding maintenance therapy, elevated levels of TIMP-1 in patients in remission were associated with relapse and/or difficulty reducing the glucocorticoid dosage after 6 to 12 months. In the MAAV-EU study, serum levels of TIMP-1 were elevated in relapsed patients 6 months before relapse, earlier than the increase in serum levels of CRP. Analyses of both studies revealed that approximately 30\% of patients in remission with a serum TIMP-1 level $\geq 150 \mathrm{ng} / \mathrm{mL}$ relapsed after 6 to 12 months, while the majority of patients with a TIMP-1 level $<150 \mathrm{ng} / \mathrm{mL}$ sustained remission for at least 12 months.

* Correspondence: ishizaki@m.ehime-u.ac.jp; hitoshih@m.ehime-u.ac.jp 'Department of Hematology, Clinical Immunology, and Infectious Diseases, Ehime University Graduate School of Medicine, Toon, Ehime 791-0295, Japan Full list of author information is available at the end of the article

(c) The Author(s). 2021 Open Access This article is licensed under a Creative Commons Attribution 4.0 International License, which permits use, sharing, adaptation, distribution and reproduction in any medium or format, as long as you give appropriate credit to the original author(s) and the source, provide a link to the Creative Commons licence, and indicate if changes were made. The images or other third party material in this article are included in the article's Creative Commons licence, unless indicated otherwise in a credit line to the material. If material is not included in the article's Creative Commons licence and your intended use is not permitted by statutory regulation or exceeds the permitted use, you will need to obtain permission directly from the copyright holder. To view a copy of this licence, visit http://creativecommons.org/licenses/by/4.0/. The Creative Commons Public Domain Dedication waiver (http://creativecommons.org/publicdomain/zero/1.0/) applies to the data made available in this article, unless otherwise stated in a credit line to the data. 
(Continued from previous page)

Conclusion: We herein demonstrated that TIMP-1 is more useful as a predictive biomarker of sustained remission than as a predictor of relapse in maintenance therapy for AAV. TIMP-1 levels $<150 \mathrm{ng} / \mathrm{mL}$ are important for the long-term maintenance of remission and may be an indicator for the tapering or cessation of treatment.

Keywords: Antineutrophil cytoplasmic antibody-associated vasculitis, Tissue inhibitor of metalloproteinase 1, Maintenance therapy, Remission, Biomarker

\section{Background}

Antineutrophil cytoplasmic antibody (ANCA)-associated vasculitis (AAV) comprises three distinct diseases: granulomatosis with polyangiitis (GPA), microscopic polyangiitis (MPA), and eosinophilic granulomatosis with polyangiitis (EGPA) [1]. Clinical relapse following remission is common in AAV [2]. ANCA and traditional acute-phase indicators, including C-reactive protein (CRP), are used in clinical practice as biomarkers of disease activity and predictors of relapse. However, these biomarkers lack the sensitivity and specificity for monitoring the disease activity of AAV [3-7]. Several circulating biomarkers for monitoring disease activity or predicting relapse have been reported in large-cohort studies and systematic literature searches [8-15]; however, none have been applied to clinical practice. Furthermore, the identification of predictors of sustained remission is important for treatment planning.

We previously identified promising biomarkers of disease activity and organ involvement in AAV using a targeted proteomics approach with serum samples collected in a Japanese nationwide large cohort study (RemIT-JAV-RPGN) [16, 17]. In a quantitative analysis of 135 biomarker candidates, tissue inhibitor of metalloproteinase 1 (TIMP-1) was the bestperforming marker of disease activity that distinguished mildly or highly active AAV from remission 6 months after the initiation of remission-induction therapy. In contrast, other markers, such as CRP and myeloperoxidase (MPO)ANCA, did not significantly differ between patients with mild activity and in remission. Monach et al. examined 28 markers associated with inflammation, angiogenesis, tissue damage, and repair in patients enrolled in the Rituximab in AAV (RAVE) study, and suggested that TIMP-1 distinguished active AAV from remission more accurately than ESR and CRP [10]. The findings of these two large-cohort studies suggest the potential of TIMP-1 for monitoring disease activity. However, TIMP-1 was only evaluated at two points, i.e., before and 6 months after the initiation of remission-induction therapy. Therefore, detailed analysis of TIMP-1 levels during the clinical course of AAV patients is needed to verify whether TIMP-1 is clinically useful as a predictor of relapse and sustained remission during maintenance therapy.

In the present study, we excluded EGPA from subjects because of its particularities, such as eosinophil inflammation and differences in the definition of relapse [18,
19], and analyzed patients with MPA and GPA. We examine the relationship between serum levels of TIMP1 at 6 months in patients in remission and clinical outcomes up to 18 months in the Japanese RemIT-JAVRPGN cohort study. We also performed a serial analysis of serum TIMP-1 levels in AAV patients receiving maintenance therapy at our hospital, and investigated whether TIMP-1 is useful as a predictor of relapse and sustained remission.

\section{Methods \\ Healthy donors and patients}

In an analysis using follow-up data from the RemITJAV-RPGN study, we assessed 69 AAV patients 6 months after treatment initiation [16]. The RemIT-JAVRPGN study is a multi-center cohort. Among 69 patients, 54 were enrolled in the RemIT-JAV-RPGN study and 15 were patients in our hospital. All patients were newly diagnosed with AAV and fulfilled the criteria for primary systemic vasculitis proposed by the European Medicine Agency (EMEA) algorithm [20], according to which the 69 patients were diagnosed as follows: 46 with MPA and 23 with GPA.

In serial analysis of serum TIMP-1 levels, we assessed 30 AAV patients receiving maintenance therapy in our hospital who were followed up for more than 12 months (the MAAV-EU study; Maintenance therapy for AAV in the Ehime University study). These patients were diagnosed as follows: 16 with MPA and 14 with GPA. All patients had achieved remission when they were enrolled in the present study. The observation period was between December 2017 and March 2020.

Patients in the RemIT-JAV-RPGN and MAAV-EU studies received remission-induction therapy and maintenance therapy based on the discretion of the site investigators according to the Japanese Ministry of Health, Labour, and Welfare (MHLW) Guidelines for the Treatment of AAV. In both studies, patients younger than 20 years and those with EGPA and/or malignancy were excluded. EGPA was excluded because of its unique characteristics, such as eosinophil inflammation, and differences in organ damage, ANCA positivity, the definition of relapse and treatment responses from MPA and GPA [18, 19]. Malignancy was excluded because of its influence on the selection of treatment and serum levels of TIMP-1. 
Serum samples were also obtained from 52 healthy donors.

\section{Outcome measures}

Details of the RemIT-JAV-RPGN study protocol were reported previously [16]. Follow-up data, including vital status, Birmingham Vasculitis Activity Score (BVAS), laboratory data, and treatment, were collected at 3, 6, 12, and 18 months of treatment and at the time of relapse. Disease activity was evaluated according to BVAS version 3 [21]. In the analysis using the follow-up data of the RemIT-JAV-RPGN study, remission 6 months after the initiation of treatment was defined as BVAS 0 on two occasions at least 1 month apart according to the EULAR recommendations [22]. Sustained remission was defined as the maintenance of remission from 6 to 18 months after the initiation of treatment. Patients with difficulties reducing the glucocorticoid (GC) dosage were defined as a daily GC dosage of $\geq 10 \mathrm{mg}$ prednisolone 18 months after treatment.

In the MAAV-EU study, sustained remission was defined as BVAS 0 from the time of enrollment to the end of the observation period (more than 12 months in remission). Baseline data for patients in sustained remission were obtained 6 months after enrollment, whereas those for relapsed patients were collected at the time of relapse. We compared serum levels of TIMP-1 and CRP between both groups 6 months $(-6 \mathrm{M}), 3$ months $(-3$ $\mathrm{M})$, and 1 month $(-1 \mathrm{M})$ before baseline and at baseline.

In both studies, relapse was defined as the reoccurrence or new onset of clinical signs and symptoms attributable to active vasculitis.

\section{Enzyme-linked immunosorbent assays (ELISA)}

Serum in patients in the RemIT-JAV-RPGN study was analyzed before and 6 months after the initiation of treatment. In the MAAV-EU study, each biomarker was analyzed using serum samples serially collected every 1 to 3 months during the observation period. Serum samples were frozen at $-80^{\circ} \mathrm{C}$ until used.

Samples were analyzed using commercially available ELISA kits according to the manufacturer's instructions. The following ELISA kits were used: CRP, TIMP-1, matrix metalloproteinase 3 (MMP-3), and C-X-C motif chemokine ligand 13 (CXCL13) (R\&D Systems, Minneapolis, MN, USA); MPO-ANCA and proteinase-3 (PR3)ANCA (MBL, Nagoya, Japan).

\section{Statistical analysis}

We used baseline and follow-up data at 6, 12, and 18 months and at relapse in the RemIT-JAV-RPGN study. Values were expressed as medians and interquartile ranges (IQR) or as numbers and percentages. Continuous non-parametric variables were compared using the
Mann-Whitney $U$ test between 2 groups and the Kruskal-Wallis test and Steel-Dwass test among 3 groups and categorical variables using Fisher's direct probability test. The distinction of active AAV from remission in the same patients with AAV was compared using the Wilcoxon signed-rank test. The receiver operating characteristic (ROC) curves were constructed using logistic regression to assess the ability of the biomarker and define the optimal cutoff point. The area under the ROC curve (AUC) was calculated. The optimal cutoff point was determined using the Youden index, which is defined as the maximum sum of sensitivity and specificity. Correlations between paired data were analyzed using Spearman's rank correlation.

A multivariable analysis was performed using a logistic regression model to adjust for confounding factors, including age, sex, AAV type, and BVAS before treatment. Relapse-free survival was analyzed using the KaplanMeier method and compared using the Log-rank test. Differences at $p<0.05$ were considered to be significant. Statistical analyses were performed using JMP software, version 15 (SAS Institute, Cary, NC, USA).

\section{Results}

Patient characteristics and relationship between serum TIMP-1 levels and clinical outcomes at 6 months in the RemIT-JAV-RPGN study

The characteristics of the 69 patients enrolled in the RemIT-JAV-RPGN study and in our hospital at baseline and 6 months after the initiation of treatment are shown in Table 1. Among these patients, $52(75 \%)$ were in remission at 6 months, whereas $17(25 \%)$ were not and had mildly active AAV (median BVAS 5 [IQR3-6]). The serum level of creatinine and estimated glomerular filtration rate (eGFR) in patients before treatment and at 6 months did not significantly differ between the two groups (before treatment, creatinine: $p=0.063$, eGFR: $p=0.063$; at 6 months, creatinine: $p=0.14$, eGFR: $p=$ 0.055). The serum levels of TIMP-1 in patients before treatment did not correlate with the serum level of creatinine or eGFR (vs creatinine: $\rho=0.01, p=0.92$; vs eGFR: $\rho=-0.04, p=0.76$ ).

As shown in Fig. 1a, serum levels of TIMP-1, CRP, and MPO-ANCA were significantly higher in patients before treatment than in those in remission at 6 months. Serum levels of TIMP-1 were significantly higher in patients before treatment than in healthy controls (302 [227-381] ng/mL vs 133 [122-150] ng/mL, $p<0.001$ ). In addition, PR3-ANCA was significantly higher in patients before treatment than in those in remission at 6 months; however, the number $(n=8)$ of PR3-ANCApositive patients was small. Serum levels of TIMP-1 were significantly higher in the 17 patients not in remission than in the 52 in remission at 6 months (182 [152-197] 
Table 1 Clinical characteristics of 69 patients at baseline and 6 months after the initiation of treatment in the RemIT-JAV-RPGN study

\begin{tabular}{|c|c|c|c|}
\hline & All patients $(n=69)$ & Remission $(n=52)$ & Not in remission $(n=17)$ \\
\hline Male/female, $n / n$ & $27 / 42$ & $22 / 30$ & $5 / 12$ \\
\hline Age, years & $69(61-77)$ & $69(61-77)$ & $67(61-73)$ \\
\hline GPA/MPA, n/n & $23 / 46$ & $16 / 36$ & $7 / 10$ \\
\hline MPO-ANCA-positive & $59(86 \%)$ & $45(87 \%)$ & $14(82 \%)$ \\
\hline PR3-ANCA-positive & $12(17 \%)$ & $8(15 \%)$ & $4(24 \%)$ \\
\hline ANCA-negative & $2(3 \%)$ & $2(4 \%)$ & $0(0 \%)$ \\
\hline Serum creatinine at baseline, $\mathrm{mg} / \mathrm{dL}$ & $0.92(0.66-1.86)$ & $0.88(0.66-1.37)$ & $1.86(0.69-4.53)$ \\
\hline Serum creatinine at 6 months, mg/dL & $0.91(0.74-1.28)$ & $0.9(0.74-1.08)$ & $1.26(0.81-1.47)$ \\
\hline eGFR at baseline, $\mathrm{mL} / \mathrm{min} / 1.73 \mathrm{~m}^{2}$ & $54(22-69)$ & $60(34-70)$ & $22(11-67)$ \\
\hline eGFR at 6 months, $\mathrm{mL} / \mathrm{min} / 1.73 \mathrm{~m}^{2}$ & $53(39-67)$ & $61(42-71)$ & $41(29-53)$ \\
\hline \multicolumn{4}{|l|}{ Disease activity and organ involvement } \\
\hline BVAS score & $15(12-22)$ & $15(12-22)$ & $19(12-22)$ \\
\hline BVAS general-positive & $52(75 \%)$ & $41(79 \%)$ & $11(65 \%)$ \\
\hline BVAS cutaneous-positive & $11(16 \%)$ & $8(15 \%)$ & $3(18 \%)$ \\
\hline BVAS mucous membranes/eyes-positive & $11(16 \%)$ & $10(19 \%)$ & $1(6 \%)$ \\
\hline BVAS ENT-positive & $28(41 \%)$ & $21(40 \%)$ & $7(41 \%)$ \\
\hline BVAS chest-positive & $28(41 \%)$ & $20(38 \%)$ & $8(47 \%)$ \\
\hline BVAS cardiovascular-positive & $4(6 \%)$ & $4(8 \%)$ & $0(0 \%)$ \\
\hline BVAS abdominal-positive & $1(1 \%)$ & $1(2 \%)$ & $0(0 \%)$ \\
\hline BVAS renal-positive & $53(77 \%)$ & $40(77 \%)$ & $13(76 \%)$ \\
\hline BVAS nervous system-positive & $23(33 \%)$ & $16(31 \%)$ & $7(41 \%)$ \\
\hline \multicolumn{4}{|l|}{ Induction therapy, 0-6 months } \\
\hline Glucocorticoids, mg/day & $45(30-50)$ & $43(30-50)$ & $45(40-50)$ \\
\hline Glucocorticoid pulse & $28(41 \%)$ & $18(35 \%)$ & $10(59 \%)$ \\
\hline Cyclophosphamide & $38(55 \%)$ & $27(52 \%)$ & $11(65 \%)$ \\
\hline MPO-ANCA negative conversion at 6 months ${ }^{a}$ & $39(70 \%)$ & $29(69 \%)$ & $10(71 \%)$ \\
\hline PR3-ANCA negative conversion at 6 months ${ }^{b}$ & 7 (58\%) & $4(50 \%)$ & $3(75 \%)$ \\
\hline
\end{tabular}

Values are medians (IQR) or $n(\%)$

Four patients had double (MPO and PR3) positive ANCA

${ }^{a}$ The rate of MPO-ANCA negative conversion was only calculated for MPO-ANCA-positive patients whose MPO-ANCA levels were measured at 6 months (all patients, $n=56$; remission, $n=42$; not in remission, $n=14$ )

${ }^{\mathrm{b}}$ The rate of PR3-ANCA negative conversion was only calculated for PR3-ANCA-positive patients whose PR3-ANCA levels were measured at 6 months (all patients, $n=12$; remission, $n=8$; not in remission, $n=4$ )

GPA, granulomatosis with polyangiitis; MPA, microscopic polyangiitis; MPO, myeloperoxidase; PR3, proteinase-3; ANCA, antineutrophil cytoplasmic antibody; eGFR, estimated glomerular filtration rate; BVAS, Birmingham Vasculitis Activity Score version 3; ENT, ear, nose, and throat

ng/mL vs 160 [139-179] ng/mL) (Fig. 1b). After adjustments for potential confounders, such as age, sex, and AAV type, using multivariable analysis, an elevated level of TIMP-1 (per $20 \mathrm{ng} / \mathrm{mL}$ increase) was still significantly associated with no remission (odds ratio [OR] 1.38 [95\% CI 1.03-1.84], $p=0.024$ ). To distinguish between these 2 groups, the TIMP-1 cutoff level for remission at 6 months was $144 \mathrm{ng} / \mathrm{mL}$ with a sensitivity of $38 \%$ and specificity of $100 \%$. In contrast, CRP, MPO-ANCA, and PR3-ANCA did not significantly differ between the 2 groups. These results suggest that TIMP-1 is a superior biomarker to CRP, MPO-ANCA, and PR3-ANCA for monitoring the disease activities of MPA and GPA.

\section{Relationship between serum TIMP-1 levels and clinical outcomes from 6 to 18 months in the RemIT-JAV-RPGN study}

We assessed the clinical outcomes of maintenance therapy from 6 to 18 months among the 52 patients in remission; 45 (31 with MPA and 14 with GPA) were followed up for at least 18 months. Of the 7 patients lost to the follow-up by 18 months, 2 died from causes other than vasculitis and 5 had missing follow-up data or interrupted visits during the observation period. Eight (16\%) patients, 6 with MPA and 2 with GPA, relapsed by 18 months: 5 from 6 to 12 months and 3 from 12 to 18 months (Table 2, Fig. 2a). The median GC dosage at 


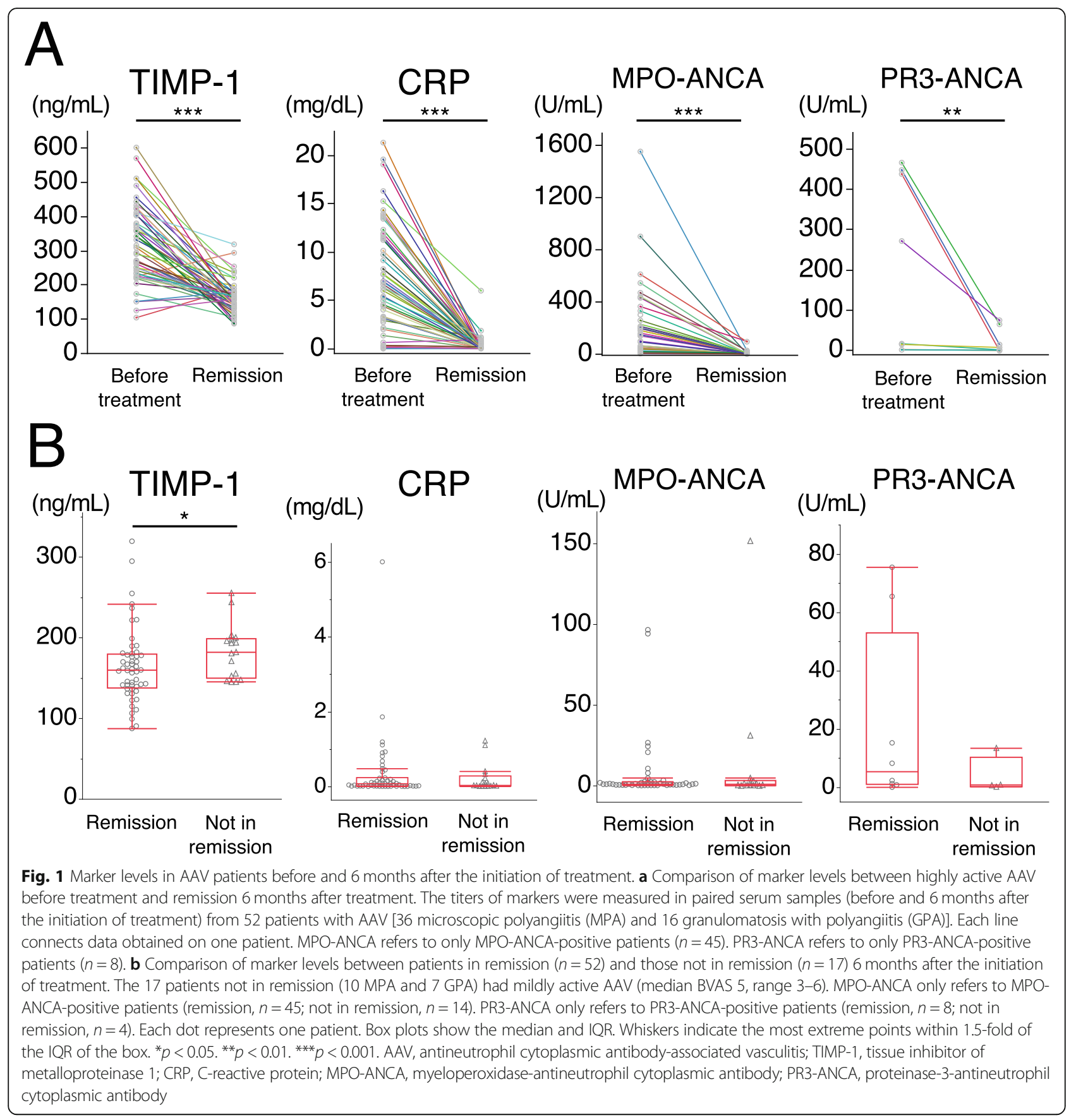

18 months in all patients in remission was 7.5 (IQR 5-9) $\mathrm{mg}$ prednisolone, and 11 patients, including 5 relapsed patients, had difficulty reducing the GC dosage (median 13 [IQR 10-15.5] mg). The use of immunosuppressants from 6 to 18 months did not significantly differ between patients with difficulty reducing GC and those in sustained remission without difficulty reducing GC. A significant difference was observed in TIMP-1 levels at 6 months among the following 3 groups: sustained remission, difficulty reducing GC, and relapse, by the Kruskal-
Wallis test $(p=0.014)$, but not in CRP. TIMP-1 levels were significantly higher in the relapse group than in the sustained remission group.

Age, the AAV type, BVAS before treatment, the serum level of creatinine, eGFR, and the use of immunosuppressants from 6 to 18 months were not significantly different between patients with relapse and/or difficulty reducing GC and those in sustained remission without difficulty reducing GC. The proportion of males was significantly higher among patients with relapse and/or 
Table 2 Clinical outcomes in patients receiving maintenance therapy in the RemIT-JAV-RPGN study

\begin{tabular}{|c|c|c|c|}
\hline & $\begin{array}{l}\text { Relapse and/or difficulty reducing GC } \\
(n=14)\end{array}$ & $\begin{array}{l}\text { Sustained remission without difficulty reducing } \\
\text { GC }(n=31)\end{array}$ & $\begin{array}{l}p \\
\text { value }^{d}\end{array}$ \\
\hline Male/female, $n / n$ & $9 / 5$ & $9 / 22$ & 0.047 \\
\hline Age, years & $68(61-72)$ & $68(61-77)$ & 0.60 \\
\hline GPA/MPA, n/n & $3 / 11$ & $11 / 20$ & 0.49 \\
\hline MPO-ANCA-positive before treatment & $13(93 \%)$ & $25(81 \%)$ & 0.41 \\
\hline PR3-ANCA-positive before treatment & $1(7 \%)$ & $7(23 \%)$ & 0.4 \\
\hline BVAS score before treatment & $18(11-25)$ & $15(12-18)$ & 0.31 \\
\hline \multicolumn{4}{|l|}{ Glucocorticoids, mg/day } \\
\hline At 6 months & $15(11-18)$ & $13(10-17)$ & 0.19 \\
\hline At 12 months & $12(10-14)$ & $7(5-10)$ & $<0.001$ \\
\hline At 18 months & $11(10-15)$ & $5(5-8)$ & $<0.001$ \\
\hline Immunosuppressants & $7(50 \%)$ & $18(58 \%)$ & 0.75 \\
\hline AZA/MTX/others, $n$ & $4 / 1 / 2$ & $13 / 0 / 10$ & \\
\hline Serum creatinine at 6 months, $\mathrm{mg} / \mathrm{dL}$ & $1.00(0.83-2.09)$ & $0.86(0.70-1.02)$ & 0.053 \\
\hline eGFR at 6 months, $\mathrm{mL} / \mathrm{min} / 1.73 \mathrm{~m}^{2}$ & $43(21-74)$ & $61(46-72)$ & 0.3 \\
\hline CRP at 6 months, mg/dL & $0.09(0.006-0.43)$ & $0.05(0.01-0.17)$ & 0.96 \\
\hline MPO-ANCA at 6 months, $\mathrm{U} / \mathrm{mL}^{\mathrm{a}}$ & $1.3(1-2)$ & $1(0.4-2.6)$ & 0.42 \\
\hline $\begin{array}{l}\text { MPO-ANCA negative conversion at } 6 \\
\text { months }{ }^{b}\end{array}$ & $10(83 \%)$ & $14(61 \%)$ & 0.48 \\
\hline TIMP-1 at 6 months, ng/mL & $176(159-216)$ & $144(135-168)$ & 0.004 \\
\hline High TIMP-1 at 6 months ${ }^{c}$ & $13(93 \%)$ & $13(42 \%)$ & 0.003 \\
\hline
\end{tabular}

Values are medians (IQR) or $n(\%)$

${ }^{a}$ Only MPO-ANCA-positive patients whose MPO-ANCA levels were measured at 6 months (relapse and/or difficulty reducing GC, $n=13$; sustained remission without difficulty reducing $\mathrm{GC}, n=25$ )

${ }^{\mathrm{b}}$ The rate of MPO-ANCA negative conversion was only calculated for MPO-ANCA-positive patients whose MPO-ANCA levels were measured at 6 months (relapse and/or difficulty reducing GC, $n=12$; sustained remission without difficulty reducing $\mathrm{GC}, n=23$ )

'Serum TIMP-1 levels at 6 months $\geq 150 \mathrm{ng} / \mathrm{mL}$

$\mathrm{d}_{p<0.05}$ was considered to be significant

GC, glucocorticoids; GPA, granulomatosis with polyangiitis; MPA, microscopic polyangiitis; MPO, myeloperoxidase; PR3, proteinase-3; ANCA, antineutrophil cytoplasmic antibody; BVAS, Birmingham Vasculitis Activity Score version 3; AZA, azathioprine; MTX, methotrexate; eGFR, estimated glomerular filtration rate; TIMP-1, tissue inhibitor of metalloproteinase 1

difficulty reducing GC than among those in sustained remission without difficulty reducing GC. Serum levels of TIMP-1 at 6 months were significantly higher in patients with relapse and/or difficulty reducing GC than in those in sustained remission without difficulty reducing GC $(p=0.004)$. The cutoff point for sustained remission without difficulty reducing $\mathrm{GC}$ was $148 \mathrm{ng} / \mathrm{mL}$ with a sensitivity of $58 \%$, specificity of $93 \%$, and AUC of 0.77 . In contrast, serum levels of CRP and MPO-ANCA at 6 months did not significantly differ between both groups. Based on healthy control data and this cutoff point, we divided patients into high $(\geq 150 \mathrm{ng} / \mathrm{mL}$ at 6 months after treatment $)$ and low $(<150 \mathrm{ng} / \mathrm{mL})$ TIMP-1 groups. In a multivariable analysis of variables including sex and the presence of elevated TIMP-1 levels at 6 months (TIMP-1 $\geq 150 \mathrm{ng} / \mathrm{mL}$ or $<150 \mathrm{ng} / \mathrm{mL}$ ), elevated TIMP-1 levels at 6 months were significantly associated with patients with relapse and/or with difficulty reducing GC from 6 to 18 months (OR 14.1 [95\% CI 1.6-125.5], $p=$ 0.003) (Table 3).
We compared clinical outcomes from 6 to 18 months between the high and low TIMP-1 groups (Fig. 2b). Among 45 patients, 26 and 19 were divided into the high and low TIMP-1 groups, respectively. There were 8 (31\%) patients with relapse, 5 (19\%) with difficulty reducing GC, and 13 (50\%) in remission without difficulty reducing GC in the high TIMP-1 group. On the other hand, all patients in the low TIMP-1 group (95\%), except for one with difficulty reducing GC, sustained remission. Relapse-free survival was significantly higher in the low TIMP-1 group than in the high TIMP-1 group (Fig. 2c). These findings suggest that patients with TIMP-1 levels $<150 \mathrm{ng} / \mathrm{mL}$ on maintenance therapy had more strongly suppressed disease activity and may be in remission for 12 months.

Serial analysis of serum TIMP-1 levels and clinical outcomes in the MAAV-EU study

To confirm the results obtained, a more detailed serial analysis of TIMP-1 levels and clinical outcomes was 


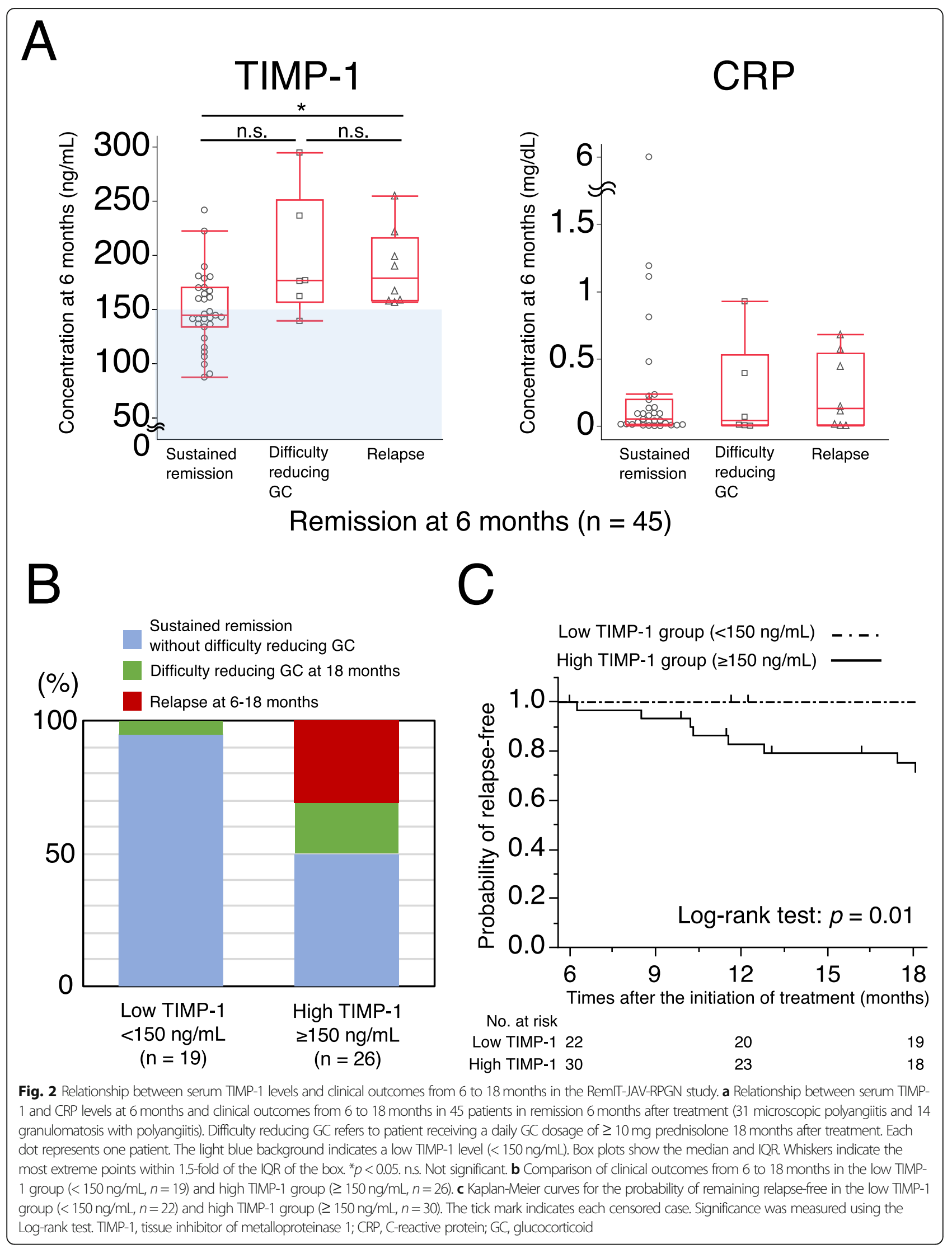


Table 3 Logistic regression analysis of patients with relapse and/or difficulty reducing glucocorticoids from 6 to 18 months

\begin{tabular}{llll}
\hline Variable & Unit & Adjusted OR (95\% Cl) & $\boldsymbol{p}$ value \\
\hline Sex & Male & $2.7(0.6-12.1)$ & 0.18 \\
High TIMP-1 at 6 months & $\geq 150 \mathrm{ng} / \mathrm{mL}$ & $14.1(1.6-125.5)$ & 0.003 \\
\hline
\end{tabular}

${ }^{a} p<0.05$ was considered to be significant

$\mathrm{OR}$, odds ratio; $\mathrm{Cl}$, confidence intervals; TIMP-1, tissue inhibitor of metalloproteinase 1

performed in AAV patients receiving maintenance therapy in our hospital using serum samples and clinical data collected every 1 to 3 months (MAAV-EU study). The characteristics of 30 AAV patients in the MAAVEU study were shown in Table 4. The median disease duration of all patients was 2.3 (IQR 1.5-8.5) years. Five out of the 30 patients (17\%), 2 with MPA and 3 with GPA, relapsed, while 25 (83\%) sustained remission during the observation period (more than 12 months) (Fig. 3a). Of the 5 relapsed patients, 3 had first relapse and the other 2 had second relapse. Characteristics, such as age, sex, and disease duration, the serum level of creatinine, and eGFR did not significantly differ between relapsed patients and patients with sustained remission. Furthermore, no significant differences were observed in the GC dosage at 6 months before baseline and the combination rate of immunosuppressants, whereas GC dosages at baseline and 3 months before baseline were significantly higher in relapsed patients. As shown in Fig. 3b, serum levels of TIMP-1 and CRP at baseline and 3 months before baseline were significantly higher in relapsed patients, whereas only TIMP-1 levels 6 months before baseline were significantly higher in relapsed patients. The median serum TIMP-1 level in relapsed patients 6 months before relapse was 205 (191-205) ng/ $\mathrm{mL}$. This result indicates that TIMP-1 levels predict the possibility of relapse earlier than CRP during maintenance therapy. The serum level of TIMP-1 at the baseline did not correlate with the serum level of creatinine or eGFR (vs creatinine: $\rho=0.2, p=0.29$; vs eGFR: $\rho=-$ $0.12, p=0.51$ ).

We compared clinical outcomes between the high $(\geq$ $150 \mathrm{ng} / \mathrm{mL} 6$ months before baseline) and low (<150 ng/ $\mathrm{mL}$ ) TIMP-1 groups in the MAAV-EU study. Thirty patients were equally divided into the high and low TIMP1 groups. As shown in Fig. 3c, 5 (33\%) patients in the high TIMP-1 group relapsed after 6 months. In contrast, all patients in the low TIMP-1 group sustained remission during the observation period.

Among the 20 MPO-ANCA-positive patients at onset in the MAAV-EU study, 15 showed the negative conversion of MPO-ANCA before enrollment, whereas 5 did not. Of the 15 patients with the negative conversion of MPO-ANCA, 4 and 1 showed the reappearance of

Table 4 Comparison of patients with relapse and sustained remission in the MAAV-EU study

\begin{tabular}{|c|c|c|c|}
\hline & Relapse $(n=5)$ & Sustained remission $(n=25)$ & $p$ value $^{\mathrm{b}}$ \\
\hline Male/female, $\mathrm{n} / \mathrm{n}$ & $2 / 3$ & $10 / 15$ & 1.0 \\
\hline Age, years & $68(65-71)$ & $66(61-72)$ & 0.40 \\
\hline Disease duration, year & $1.9(1.1-2.1)$ & $3.5(1.5-11.7)$ & 0.062 \\
\hline Previous history of relapse & $2(40 \%)$ & $7(28 \%)$ & 0.62 \\
\hline GPA/MPA, n/n & $3 / 2$ & $11 / 14$ & 0.64 \\
\hline MPO-ANCA-positive at onset & $4(80 \%)$ & $16(64 \%)$ & 0.64 \\
\hline PR3-ANCA-positive at onset & $1(20 \%)$ & $7(28 \%)$ & 1.0 \\
\hline Serum creatinine at baseline, $\mathrm{mg} / \mathrm{dL}$ & $0.75(0.59-0.92)$ & $1.0(0.69-0.95)$ & 0.34 \\
\hline eGFR at baseline, mL/min/1.73 m² & $78(63-80)$ & $65(50-68)$ & 0.22 \\
\hline MPO-ANCA negative conversion at enrollment ${ }^{a}$ & $3(75 \%)$ & $8(53 \%)$ & 0.60 \\
\hline Glucocorticoids at -6 months, mg/day & $10(9-10)$ & $5(5-10)$ & 0.36 \\
\hline Glucocorticoids at -3 months, mg/day & $9(9-10)$ & $5(5-8)$ & 0.035 \\
\hline Glucocorticoids at baseline, mg/day & $9(8-10)$ & $5(5-6)$ & 0.019 \\
\hline Immunosuppressants & $3(60 \%)$ & $18(72 \%)$ & 0.62 \\
\hline
\end{tabular}

Values are medians (IQR) or $n(\%)$

${ }^{a}$ The rate of MPO-ANCA negative conversion was only calculated for MPO-ANCA-positive patients whose MPO-ANCA levels were measured at enrollment (relapse, $n=4$; sustained remission, $n=15$ )

${ }^{\mathrm{b}} p<0.05$ was considered to be significant

MAAV-EU study, maintenance therapy for antineutrophil cytoplasmic antibody-associated vasculitis in the Ehime University study; GPA, granulomatosis with polyangiitis; MPA, microscopic polyangiitis; MPO, myeloperoxidase; PR3, proteinase-3; ANCA, antineutrophil cytoplasmic antibody; eGFR, estimated glomerular filtration rate 


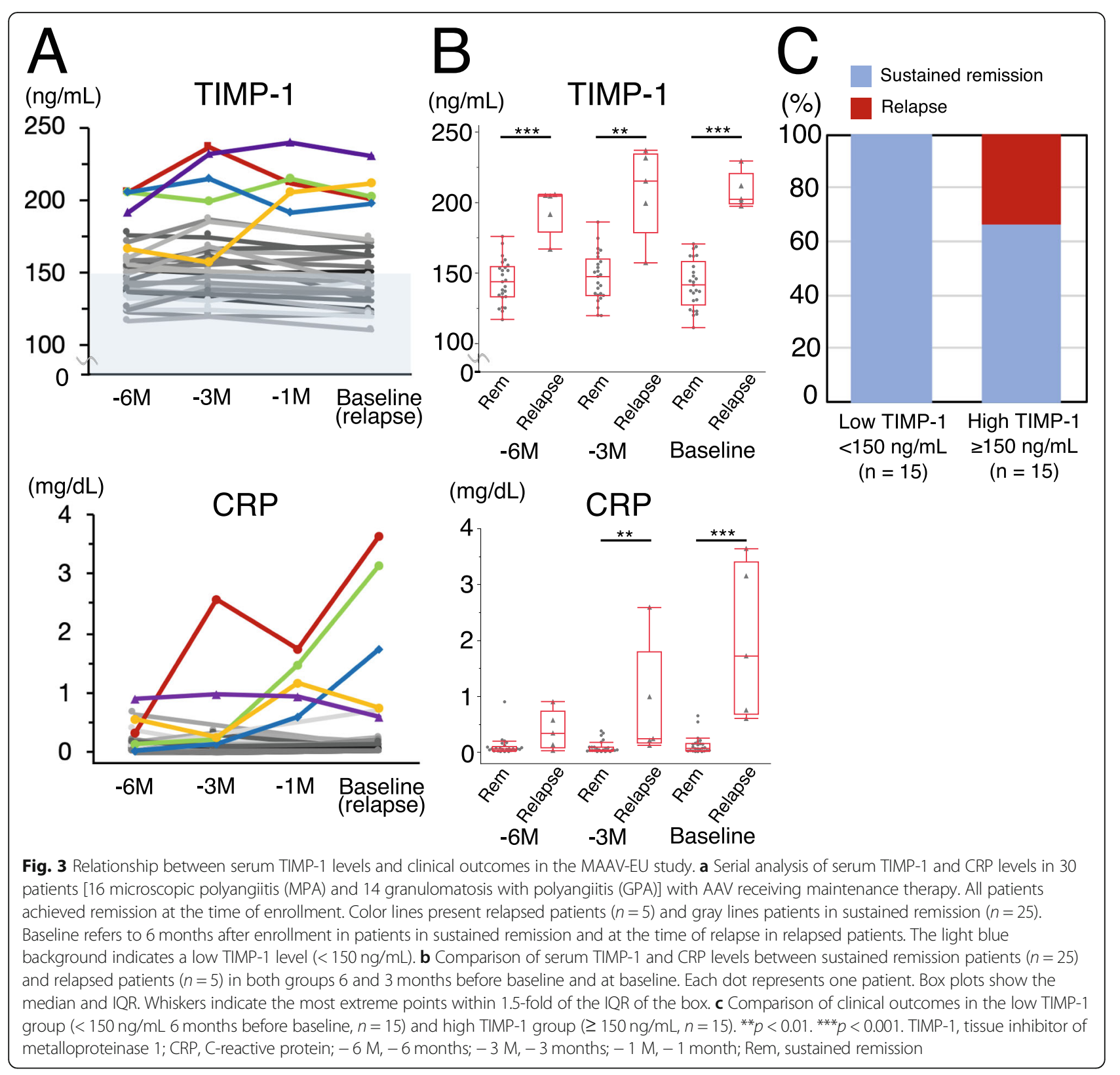

MPO-ANCA at enrollment and 1 month after enrollment, respectively, while the remaining 10 remained MPO-ANCA negative. One (25\%) out of the 4 patients with relapse and $4(36 \%)$ out of the 11 without relapse showed the reappearance of MPO-ANCA. The reappearance rate of MPO-ANCA did not significantly differ between the two groups. All 5 patients without negative conversion did not relapse. Among the 8 PR3-ANCApositive patients at onset, 5 showed the negative conversion of PR3-ANCA at enrollment and 3 did not. All 5 patients with the negative conversion of PR3-ANCA remained negative for PR3-ANCA and maintained remission. One out of the 3 patients without the negative conversion of PR3-ANCA relapsed.
Analyses of the RemIT-JAV-RPGN and MAAV-EU studies revealed that approximately $30 \%$ of patients in remission with a serum TIMP-1 level $\geq 150 \mathrm{ng} / \mathrm{mL}$ relapsed after 6 to 12 months, while the majority of patients with a TIMP-1 level $<150 \mathrm{ng} / \mathrm{mL}$ sustained remission for at least 12 months. Therefore, a serum TIMP- 1 level $<150 \mathrm{ng} / \mathrm{mL}$ reflects complete remission, while that of $\geq 150 \mathrm{ng} / \mathrm{mL}$ indicates subclinical inflammation, even with BVAS 0, during maintenance therapy in AAV.

Serum levels of MMP-3 and CXCL13 in the RemIT-JAVRPGN and MAAV-EU studies

In addition to TIMP-1, MMP-3 and CXCL13 have been identified as useful biomarkers that discriminate active 
AAV from remission [10]. We examined the serum levels of MMP-3 and CXCL13 in both studies.

In the RemIT-JAV-RPGN study, the serum levels of MMP-3 and CXCL13 were significantly higher in patients before treatment than in healthy controls (MMP3: $29.6[16.7-46.3] \mathrm{ng} / \mathrm{mL}$ vs $16.5[11.0-24.6] \mathrm{ng} / \mathrm{mL}$, $p<0.001$; CXCL13: 189.4 [113.6-242.4] $\mathrm{pg} / \mathrm{mL}$ vs 67.6 [48.8-94.6] pg/mL, $p<0.001)$. As shown in Fig. 4a, the serum levels of MMP-3 were significantly higher in patients in remission at 6 months than in those before treatment. Serum levels of CXCL13 did not significantly differ between the groups of patients before treatment and in remission at 6 months and increased in 27 (52\%) out of 52 patients in remission at 6 months. MMP-3 and CXCL13 levels did not significantly differ between patients in remission and those not in remission at 6 months (Fig. 4b). Serum levels of MMP-3 in 52 patients in remission at 6 months correlated with the GC dosage at 6 months $(\rho=0.51, p<0.001)$, whereas those of CXCL13 did not. A significant difference was observed in MMP-3 levels at 6 months among the following 3 groups: sustained remission, difficulty reducing $\mathrm{GC}$, and relapse, by the Kruskal-Wallis test $(p=0.003)$, but not in CXCL13. MMP-3 levels were significantly higher in the difficulty reducing GC group than in the other 2 groups (See Supplementary Figure 1, Additional file 1).

In the MAAV-EU study, serum levels of MMP-3 and CXCL13 at baseline and 3 and 6 months before baseline did not significantly differ between relapsed patients and patients with sustained remission (See Supplementary Figure 2, Additional file 1).

\section{Discussion}

Relapse is common in AAV and requires repeated remission-induction therapy [2]. Although the definition of clinical remission may appear to be straightforward, many patients in remission still exhibit persistent inflammatory and immunological activities. BVAS is a common clinical indicator for evaluating disease activity in $\mathrm{AAV}$, and remission is defined as a BVAS score of 0 [21]. However, true remission may not be achieved in many patients with BVAS 0 and persistent inflammation may increase the risk of subsequent relapse.

ANCA is often used to evaluate disease activity; however, its utility for predicting relapse is limited [2, 7, 2327]. Large cohorts identified PR3-ANCA, but not MPOANCA, as an independent risk factor for relapse [2326]. In the serial analysis of PR3-ANCA in the RAVE study, an elevated PR3-ANCA titer was a poor predictor of subsequent relapse within the overall population, but was predictive of relapse in patients with renal disease or alveolar hemorrhage [26]. In two prospective Japanese cohorts, the reappearance of MPO-ANCA was significantly associated with relapse, and was particularly useful for predicting relapse in patients with renal involvement [27]. However, among 25 relapsed patients after negative conversion of MPO-ANCA, 6 (24\%) patients did not experience reappearance of MPO-ANCA. On the other hand, among 76 patients without negative conversion of MPO-ANCA, 60 patients (79\%) maintained remission. Based on these findings, ANCA shows limited utility for predicting relapse and is rarely used as a predictor of sustained remission. In the MAAV-EU study, the rate of reappearance after the negative conversion of MPO-ANCA did not significantly differ between the groups of patients in relapse and not in relapse. Watanabe et al. examined new-onset patients who were in remission 6 months after induction therapy and reported that $84 \%$ of patients with relapse had renal involvement [27]. On the other hand, in the MAAV-EU study that analyzed patients receiving maintenance therapy with a median disease duration of 2.3 years, only 1 out of 5 patients with relapse had renal involvement. These discrepancies in the results obtained may be attributed to differences in the subject groups.

Previous studies investigated predictive markers of relapse other than ANCA. In the RAVE study, an increase in serum calprotectin levels by 2 or 6 months was predictive of relapse by 18 months in PR3-ANCA-positive AAV patients treated with rituximab. However, this marker was not useful in patients treated with oral cyclophosphamide [14]. The CD8 T-cell transcription signature was associated with subsequent relapse in AAV or systemic lupus erythematosus, but requires further prospective validation [28].

In the two large cohort studies, the Japanese RemITJAV-RPGN study (our previous study) [17] and RAVE study [10], TIMP-1 levels were a useful biomarker for distinguishing mildly or highly active AAV from remission 6 months after the initiation of remission-induction therapy regardless of differences in the population, such as AAV type, ANCA type, and treatment. In our previous study, TIMP-1 correlated with the total BVAS score before treatment and was less likely to be elevated in bacterial infections than CRP. In contrast, CRP, ESR, and MPO-ANCA were unable to distinguish patients with mildly active AAV from those in remission.

In the present study, we examined whether TIMP-1 levels are clinically useful as a predictor of relapse and sustained remission during maintenance therapy. Based on the results of an 18-month follow-up in the RemITJAV-RPGN cohort study, elevated TIMP-1 levels at 6 months were associated with relapse and/or difficulty reducing GC from 6 to 18 months. In the MAAV-EU study, TIMP-1 levels were significantly higher in relapsed patients 6 months before relapse than in sustained remission patients. Based on these findings, many patients with relapse have elevated TIMP-1 levels 6 months 
MMP-3

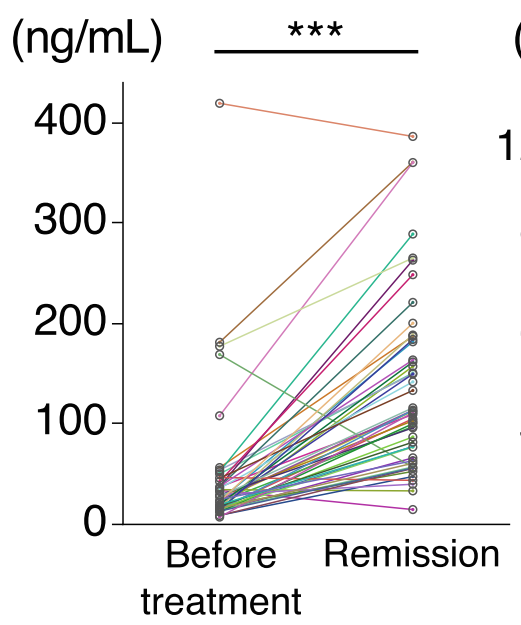

B

\section{MMP-3}

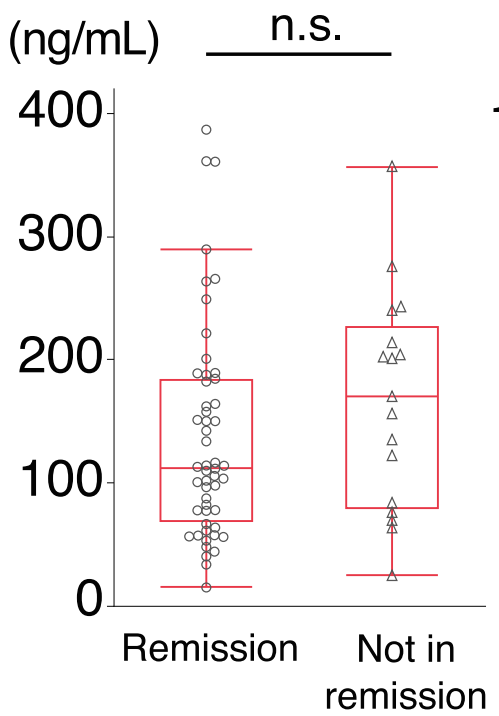

CXCL13

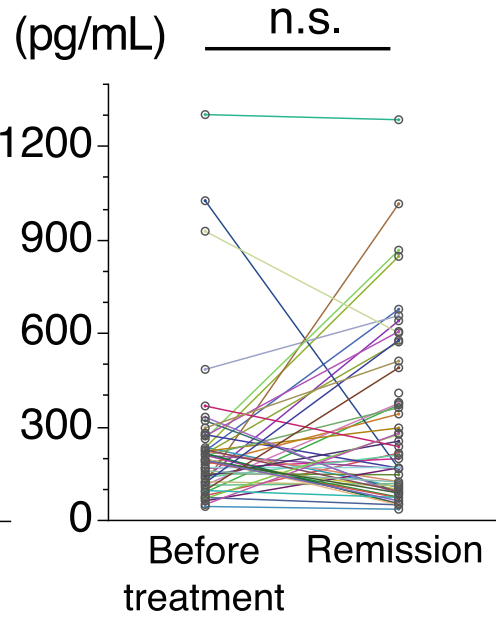

CXCL13

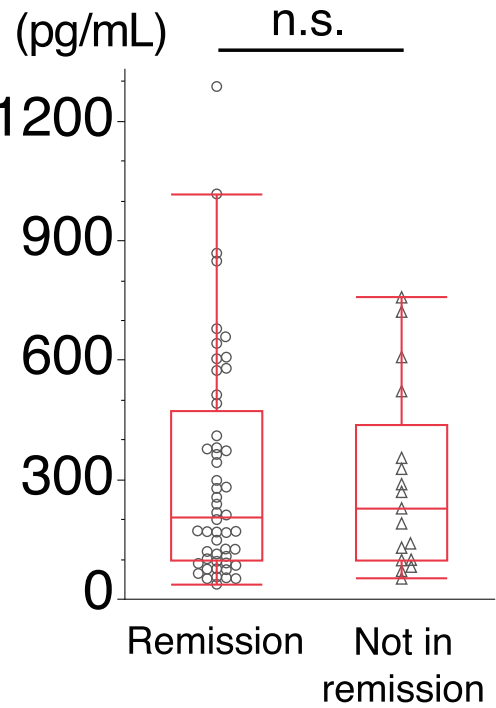

Fig. 4 Serum levels of MMP-3 and CXCL13 in AAV patients before and 6 months after the initiation of treatment. a Comparison of MMP-3 and CXCL13 levels between highly active AAV before treatment and remission 6 months after treatment. The titers of markers were measured in paired serum samples (before and 6 months after the initiation of treatment) from 52 patients with AAV [36 microscopic polyangiitis (MPA) and 16 granulomatosis with polyangiitis (GPA)]. Each line connects data obtained on one patient. b Comparison of MMP-3 and CXCL13 levels between patients in remission $(n=52)$ and those not in remission $(n=17) 6$ months after the initiation of treatment. The 17 patients not in remission (10 MPA and 7 GPA) had mildly active AAV (median BVAS 5, range 3-6). Each dot represents one patient. Box plots show the median and IQR. Whiskers indicate the most extreme points within 1.5 -fold of the IQR of the box. ${ }^{* *} p<0.001$. n.s. Not significant. AAV, antineutrophil cytoplasmic antibody-associated vasculitis

before relapse. However, elevated TIMP-1 levels were observed in some patients in sustained remission.

Since the cutoff point for sustained remission without difficulty reducing GC was $148 \mathrm{ng} / \mathrm{mL}$, patients in remission were divided into two groups of TIMP-1 levels, $\geq$
$150 \mathrm{ng} / \mathrm{mL}$ and $<150 \mathrm{ng} / \mathrm{mL}$, and their relationship with clinical outcomes was examined. In the analysis of both studies, approximately $30 \%$ of patients in remission with a TIMP-1 level $\geq 150 \mathrm{ng} / \mathrm{mL}$ relapsed after 6 to 12 months. More importantly, the majority of patients with 
a TIMP-1 level $<150 \mathrm{ng} / \mathrm{mL}$, which meant a decrease to a level approximating that in healthy controls, remained in remission for at least 12 months. Therefore, a serum TIMP-1 level $<150 \mathrm{ng} / \mathrm{mL}$ reflects complete remission, whereas $\geq 150 \mathrm{ng} / \mathrm{mL}$ indicates subclinical inflammation. Moreover, TIMP-1 levels are more useful as a predictor of sustained remission than of relapse. During maintenance therapy, TIMP-1 levels $<150 \mathrm{ng} / \mathrm{mL}$ are an important indicator of the long-term maintenance of remission. Thus, in patients with AAV, the maintenance of a TIMP-1 level $<150 \mathrm{ng} / \mathrm{mL}$ may allow for the tapering or cessation of treatment.

TIMP-1 is expressed by various cell types in most human tissues. It is an endogenous inhibitor of MMPs and its production increases in response to an increase in MMPs. In addition, it is a well-known regulator of extracellular matrix turnover, tissue remodeling, inflammation, cell growth, apoptosis, and cellular behavior in tissue [29-31]. Therefore, TIMP-1 levels may more accurately reflect the condition of inflammatory sites than CRP; however, the underlying mechanisms have not yet been elucidated. The normalization of TIMP-1 levels may indicate that vascular inflammation has completely subsided. On the other hand, serum levels of TIMP1 were previously reported to be elevated in patients with various cancers, myocardial infarction, ischemic stroke, and sepsis [29-36]. Therefore, it is important to note that TIMP-1 may not serve as a predictor of sustained remission in AAV patients with these disorders.

Monach et al. suggested that TIMP-1, MMP-3, and CXCL13 distinguished active AAV from remission more accurately than ESR and CRP in patients enrolled in the RAVE study [10]. Similar to the analysis in the RAVE study, serum levels of MMP-3 and CXCL13 in the present study were significantly higher in new-onset active AAV patients before treatment than in healthy controls. However, MMP-3 and CXCL13 were not useful for distinguishing between active AAV and remission 6 months after the initiation of treatment or for evaluating disease activity in patients receiving maintenance therapy. This is because glucocorticoids increase the serum levels of MMP-3 and CXCL13 regardless of disease activity in AAV patients. Although the underlying mechanisms remain unclear, previous studies reported that glucocorticoids increased serum MMP-3 levels [37-39] and also that glucocorticoids were associated with elevated CXCL13 levels in multiple diseases, including vasculitis [40]. In AAV patients in the RAVE study, $85 \%$ of those in remission discontinued prednisolone. Therefore, serum MMP-3 and CXCL13 levels were affected less by glucocorticoids and reflected disease activity. In contrast, neither marker accurately reflected disease activity in the present study because all patients, except for one at 6 months, in the RemIT-JAV-RPGN study and all patients in the MAAV-EU study received glucocorticoids. The present study also suggested that both disease activity and glucocorticoids increased MMP-3 and CXCL13 levels, which may limit their clinical usefulness as activity markers.

The present study has several limitations. The sample size was small in both studies. We validated the results obtained across two different cohorts of AAV, which is a rare disease; however, validation in a larger cohort is needed in the future. Furthermore, in the analysis of clinical outcomes in the Remit-JAV-RPGN study, 7 patients were lost to the follow-up by 18 months due to death, were missing follow-up data, or had interrupted visits during the observation period. Moreover, since the number of PR3-ANCA-positive patients was small in both studies, comparative analysis with PR3-ANCA could not be performed sufficiently. The small number is because MPA is the predominant type among patients with AAV in Japan and more than $80 \%$ of Japanese AAV patients are positive for pANCA/MPO-ANCA [16, 41, 42]. Since these limitations are often difficult to avoid in clinical research involving rare diseases, such as AAV, we expect TIMP-1 to become a predictor of sustained remission during maintenance therapy and contribute to treatment strategies for AAV.

\section{Conclusions}

We assessed the usefulness of serum TIMP-1 levels as a predictive biomarker of relapse and sustained remission in AAV patients during maintenance therapy. Analyses of the RemIT-JAV-RPGN and MAAV-EU studies revealed that serum TIMP-1 levels in relapsed patients were elevated 6 months before relapse, earlier than the increase in serum levels of CRP. More importantly, the majority of patients with a TIMP-1 level $<150 \mathrm{ng} / \mathrm{mL}$ maintained remission for at least 12 months, indicating complete remission. Therefore, TIMP-1 levels are more useful as a predictive biomarker of sustained remission than as a predictor of relapse in maintenance therapy for AAV. TIMP-1 levels $<150 \mathrm{ng} / \mathrm{mL}$ are an important indicator of the long-term maintenance of remission and treatment strategies.

\footnotetext{
Abbreviations

AAV: Antineutrophil cytoplasmic antibody-associated vasculitis;

ANCA: Antineutrophil cytoplasmic antibody; BVAS: Birmingham vasculitis activity score version 3; CRP: C-reactive protein; CXCL13: C-X-C motif chemokine ligand 13; EGPA: Eosinophilic granulomatosis with polyangiitis; EMEA: European Medicine Agency; GC: Glucocorticoid; GPA: Granulomatosis with polyangiitis; IQR: Interquartile range; MAAV-EU study: Maintenance therapy for AAV in the Ehime University study; MHLW: The Japanese Ministry of Health, Labour, and Welfare; MMP: Matrix metalloproteinase; MPA: Microscopic polyangiitis; MPO: Myeloperoxidase; PR3: Proteinase-3; RAVE study: The Rituximab in ANCA-Associated Vasculitis study; RemIT-JAVRPGN: Cohort study of remission induction therapy in Japanese patients with
} 
AAV and rapidly progressive glomerulonephritis; ROC: Receiver operating characteristic; TIMP-1: Tissue inhibitor of metalloproteinase-1

\section{Supplementary Information}

The online version contains supplementary material available at https://doi. org/10.1186/s13075-021-02471-5.

Additional file 1: Supplementary Figure 1. Relationship between serum MMP-3 and CXCL13 levels and clinical outcomes from 6 to 18 months in the RemIT-JAV-RPGN study. Supplementary Figure 2. Relationship between serum MMP-3 and CXCL13 levels and clinical outcomes in the MAAV-EU study.

\section{Acknowledgements}

We appreciate Dr. Keiko Tanaka (Department of Epidemiology and Preventive Medicine, Ehime University Graduate School of Medicine) for help with statistical analysis and Ms. Suzuna Matsuhiro for providing excellent technical assistance. We appreciate Dr. Seiichi Matsuo (Division of Nephrology, Department of Internal Medicine, Nagoya University Graduate School of Medicine, Nagoya, Japan), Dr. Yukio Yuzawa (Department of Nephrology, Fujita Health University School of Medicine, Aichi, Japan), and Dr. Yoshinari Takasaki (Department of Rheumatology, Juntendo University Koshigaya Hospital, Saitama, Japan) for support with the experimental design.

Research Committee of Intractable Vasculitis Syndrome and Research Committee of Intractable Renal Disease of the Ministry of Health, Labour, and Welfare of Japan: In addition to the authors, the following investigators and institutions participated in this study: Department of Rheumatology, Shimane University Faculty of Medicine (Yohko Murakawa); Center for Nephrology and Urology, Division of Nephrology and Dialysis, Kitano Hospital, Tazuke Kofukai Medical Research Institute (Eri Muso); Department of Hematology, Oncology, Nephrology, and Rheumatology, Akita University School of Medicine (Atsushi Komatsuda); Niigata Rheumatic Center (Satoshi Ito); Department of Clinical Immunology and Rheumatology, Wakayama Medical University (Takao Fujii); Department of Immunology and Rheumatology, Clinical Neuroscience and Neurology, Endocrinology and Metabolism, Nagasaki University Graduate School of Biomedical Sciences (Atsushi Kawakami); Department of Nephrology, Iwate Prefectural Central Hospital (Izaya Nakaya); Division of Nephrology and Rheumatology, Department of Internal Medicine, Fukuoka University School of Medicine (Takao Saito); Shimane University, Faculty of Medicine, Division of Nephrology (Takafumi Ito); Department of Hemodialysis and Apheresis, Yokohama City University Medical Center (Nobuhito Hirawa); Center for Rheumatology, Okayama Saiseikai General Hospital (Masahiro Yamamura); Department of Medical Technology, School of Health Sciences, Faculty of Medicine, Niigata University (Masaaki Nakano); Department of Medicine, Kidney Center, Tokyo Women's Medical University (Kosaku Nitta); Division of Nephrology and Hypertension, Kashiwa Hospital, Jikei University (Makoto Ogura); Department of Nephrology, Nagoya City University Graduate Schoo of Medical Sciences (Taio Naniwa); Division of Rheumatology and Allergology, Department of Internal Medicine, St. Marianna University School of Medicine (Shoichi Ozaki); Apheresis and Dialysis Center, Keio University School of Medicine (Junichi Hirahashi); Third Department of Interna Medicine, Division of Immunology and Rheumatology, Hamamatsu University School of Medicine, Hamamatsu (Noriyoshi Ogawa); Division of Kidney and Hypertension, Department of Internal Medicine, Jikei University School of Medicine (Tatsuo Hosoya); Division of Nephrology, Department of Laboratory Medicine, Institute of Medical, Pharmaceutical and Health Sciences, Faculty of Medicine, Kanazawa University (Takashi Wada); Division of Nephrology, Department of Internal Medicine, Juntendo University Faculty of Medicine (Satoshi Horikoshi); Institute of Rheumatology, Tokyo Women's Medical University (Yasushi Kawaguchi); Division of Clinical Immunology, Graduate School of Comprehensive Human Sciences, University of Tsukuba (Taichi Hayashi); Department of Nephrology, Tokyo Medical University Hachioji Medical Center (Masaharu Yoshida); Department of Nephrology, Hypertension, Diabetology, Endcrinology and Metabolic, Fukushima Medica University (Tsuyoshi Watanabe); Department of Nephrology, Japanese Red Cross Nagoya Daini Hospital (Daijo Inaguma); Department of Integrated Therapy for Chronic Kidney Disease, Kyushu University (Kazuhiko Tsuruya);
Niigata Prefectural Shibata Hospital (Noriyuki Homma); Division of Rheumatology, Department of Internal Medicine, Keio University School of Medicine (Tsutomu Takeuchi); Cardiovascular Respiratory and Neurology Division, Department of Internal Medicine, Asahikawa Medical University (Naoki Nakagawa); Kurobe City Hospital (Shinichi Takeda); Fukuoka Higashi Medical Center (Ritsuko Katabuchi); Division of Nephrology, Department of Medicine, Faculty of Medical Sciences, University of Fukui (Masayuki Iwano) Division of Rheumatology, Endocrinology and Nephrology at the Graduate School of Medicine, Hokkaido University (Tatsuya Atsumi); Department of Hemovascular Medicine and Artificial Organs, Faculty of Medicine, Miyazaki University (Shoichi Fujimoto); Division of Rheumatology and Nephrology, Department of Internal Medicine, Aichi Medical School of Medicine (Shogo Banno); Department of Lifetime Clinical Immunology, Graduate School of Medical and Dental Sciences, Tokyo Medical and Dental University (Takahiko Sugihara); Department of Nephrology, Tokyo Medical University Ibaraki Medical Center (Masaki Kobayashi); Department of Nephrology, Faculty of Medicine, University of Tsukuba (Kunihiro Yamagata); Department of Respiratory Medicine, Toho University Omori Medical Center (Sakae Homma); Division of Endocrinology and Metabolism, Hematology, Rheumatology and Respiratory Medicine, Department of Internal Medicine, Faculty of Medicine, Kagawa University (Hiroaki Dobashi); Department of Nephrology, Nagoya University Hospital (Naotake Tsuboi); Faculty of Health Sciences, Hokkaido University (Akihiro Ishizu); Department of Chronic Kidney Disease and Peritoneal Dialysis, Okayama University Graduate School of Medicine (Hitoshi Sugiyama).

\section{Authors' contributions}

$\mathrm{HH}$ designed the study, collected the samples and clinical data, conducted the laboratory experiments, analyzed the data, and drafted the manuscript. J conducted the laboratory experiments, performed the statistical analyses, analyzed the data, and drafted the manuscript. AT, KH, DH, KS, TM, and NT conducted the laboratory experiments. KS, KA, MH, and YA provided human patient samples and clinical data. KS, KA, MH, YA, HM, and KT edited the manuscript. All authors read and approved the final manuscript.

\section{Funding}

This work was supported by Japan Society for the Promotion of Science (JSPS) KAKENHI Grant Number JP17K16209 and the grants from the Japan Agency for Medical Research and Development (AMED): the study group for strategic exploration of drug seeds for ANCA-associated vasculitis and construction of clinical evidence (Grant Number JP17ek0109104) and the multitiered study to address clinical questions for management of intractable vasculitides (Grant Number JP20ek0109360).

\section{Availability of data and materials}

All data generated or analyzed during this study are included in this published article.

\section{Declarations}

Ethics approval and consent to participate

Approval for this study was obtained from the Institutional Review Board of Ehime University Hospital (approval number 1601029, 1609008). Written informed consent was obtained in accordance with the Declaration of Helsinki.

\section{Consent for publication}

Not applicable

\section{Competing interests}

$\mathrm{MH}$ has received unrestricted research grants from AbbVie Japan GK, Asahi Kasei Co. Medical Ltd., Ayumi Pharmaceutical Co.; Bristol Myers Squibb Co., Ltd.; Chugai Pharmaceutical Co., Ltd., Eisai Co., Ltd., Nippon Kayaku Co., Ltd.; Mitsubishi Tanabe Pharma Co.; Taisho Pharmaceutical Co., Ltd., Takeda Pharmaceutical Co., Ltd., and Teijin Pharma Ltd. MH has received speaker's fee from AbbVie Japan GK, Ayumi Pharmaceutical Co., Boehringer Ingelheim Japan, Inc., Bristol Myers Squibb Co., Ltd., Chugai Pharmaceutical Co., Ltd., Eisai Co., Ltd., Eli Lilly Japan K.K., GlaxoSmithKline K.K., Kissei Pharmaceutical Co., Ltd., Oxford Immuotec, Pfizer Japan Inc., and Teijin Pharma Ltd. HM is a consultant for AbbVie, Boehringer-Ingelheim, and Teijin Pharma. Others have declared that no conflict of interest exists. 


\section{Author details}

'Department of Hematology, Clinical Immunology, and Infectious Diseases, Ehime University Graduate School of Medicine, Toon, Ehime 791-0295, Japan. ${ }^{2}$ Division of Analytical Bio-Medicine, Advanced Research Support Center, Ehime University, Toon, Ehime, Japan. ${ }^{3}$ Department of Clinical Epidemiology, Kochi Medical School, Kochi, Japan. ${ }^{4}$ Department of Rheumatology and Clinical Immunology, Saitama Medical Center, Saitama Medical University, Saitama, Japan. ${ }^{5}$ Department of Rheumatology, Tokyo Women's Medical University School of Medicine, Tokyo, Japan. ${ }^{6}$ Department of Nephrology and Rheumatology, Kyorin University School of Medicine, Tokyo, Japan. ${ }^{7}$ Department of Internal Medicine, Kichijoji Asahi Hospital, Tokyo, Japan. ${ }^{8}$ Okayama University, Okayama, Japan.

Received: 29 July 2020 Accepted: 2 March 2021 Published online: 20 March 2021

\section{References}

1. Jennette JC, Falk RJ, Bacon PA, Basu N, Cid MC, Ferrario F, Flores-Suarez LF, Gross WL, Guillevin L, Hagen EC, Hoffman GS, Jayne DR, Kallenberg CGM, Lamprecht P, Langford CA, Luqmani RA, Mahr AD, Matteson EL, Merkel PA, Ozen S, Pusey CD, Rasmussen N, Rees AJ, Scott DGl, Specks U, Stone JH, Takahashi K, Watts RA. 2012 Revised International Chapel Hill Consensus Conference Nomenclature of Vasculitides. Arthritis Rheum. 2013;65(1):1-11. https://doi.org/10.1002/art.37715.

2. Salama AD. Relapse in anti-neutrophil cytoplasm antibody (ANCA)associated vasculitis. Kidney Int Rep. 2020;5(1):7-12. https://doi.org/10.1016/j. ekir.2019.10.005.

3. Falk RJ, Hoffman GS. Controversies in small vessel vasculitis--comparing the rheumatology and nephrology views. Curr Opin Rheumatol. 2007;19(1):1-9. https://doi.org/10.1097/BOR.0b013e328011cb80.

4. Boomsma MM, Stegeman CA, van der Leij MJ, Oost W, Hermans J Kallenberg CG, et al. Prediction of relapses in Wegener's granulomatosis by measurement of antineutrophil cytoplasmic antibody levels: a prospective study. Arthritis Rheum. 2000;43(9):2025-33. https://doi.org/10.1002/15290131(200009)43:9<2025::AID-ANR13>3.0.CO;2-O.

5. Girard T, Mahr A, Noël LH, Cordier JF, Lesavre P, André MH, Guillevin L. Are antineutrophil cytoplasmic antibodies a marker predictive of relapse in Wegener's granulomatosis? A prospective study. Rheumatology (Oxford). 2001;40(2):147-51. https://doi.org/10.1093/rheumatology/40.2.147.

6. Birck R, Schmitt WH, Kaelsch IA, van der Woude FJ. Serial ANCA determinations for monitoring disease activity in patients with ANCAassociated vasculitis: systematic review. Am J Kidney Dis. 2006;47(1):15-23. https://doi.org/10.1053/j.ajkd.2005.09.022.

7. Tomasson G, Grayson PC, Mahr AD, Lavalley M, Merkel PA. Value of ANCA measurements during remission to predict a relapse of ANCA-associated vasculitis--a meta-analysis. Rheumatology (Oxford). 2012;51(1):100-9. https:// doi.org/10.1093/rheumatology/ker280.

8. Yates M, Watts RA, Bajema IM, Cid MC, Crestani B, Hauser T, Hellmich B, Holle JU, Laudien M, Little MA, Luqmani RA, Mahr A, Merkel PA, Mills J, Mooney J, Segelmark M, Tesar V, Westman K, Vaglio A, Yalçındağ N, Jayne DR, Mukhtyar C. EULAR/ERA-EDTA recommendations for the management of ANCA-associated vasculitis. Ann Rheum Dis. 2016;75(9):1583-94. https:// doi.org/10.1136/annrheumdis-2016-209133.

9. Monach PA, Tomasson G, Specks U, Stone JH, Cuthbertson D, Krischer J, Ding L, Fervenza FC, Fessler BJ, Hoffman GS, Ikle D, Kallenberg CGM, Langford CA, Mueller M, Seo P, St.Clair EW, Spiera R, Tchao N, Ytterberg SR, Gu YZ, Snyder RD, Merkel PA. Circulating markers of vascular injury and angiogenesis in antineutrophil cytoplasmic antibody-associated vasculitis. Arthritis Rheum. 2011;63(12):3988-97. https://doi.org/10.1002/art.30615.

10. Monach PA, Warner RL, Tomasson G, Specks U, Stone JH, Ding L, Fervenza FC, Fessler BJ, Hoffman GS, Iklé D, Kallenberg CGM, Krischer J, Langford CA, Mueller M, Seo P, St. Clair EW, Spiera R, Tchao N, Ytterberg SR, Johnson KJ, Merkel PA. Serum proteins reflecting inflammation, injury and repair as biomarkers of disease activity in ANCA-associated vasculitis. Ann Rheum Dis. 2013;72(8):1342-50. https://doi.org/10.1136/annrheumdis-2012-201981.

11. Gou SJ, Yuan J, Chen M, Yu F, Zhao MH. Circulating complement activation in patients with anti-neutrophil cytoplasmic antibody-associated vasculitis. Kidney Int. 2013;83(1):129-37. https://doi.org/10.1038/ki.2012.313.

12. Brix SR, Stege G, Disteldorf E, Hoxha E, Krebs C, Krohn S, Otto B, Klätschke K, Herden E, Heymann F, Lira SA, Tacke F, Wolf G, Busch M, Jabs WJ, Özcan F, Keller F, Beige J, Wagner K, Helmchen U, Noriega M, Wiech T, Panzer U,
Stahl RAK. CC chemokine ligand 18 in ANCA-associated crescentic GN. J Am Soc Nephrol. 2015;26(9):2105-17. https://doi.org/10.1681/ASN.2014040407.

13. Villacorta J, Diaz-Crespo F, Acevedo M, Cavero T, Guerrero C, Praga M, Fernandez-Juarez G. Circulating C3 levels predict renal and global outcome in patients with renal vasculitis. Clin Rheumatol. 2016;35(11):2733-40. https://doi.org/10.1007/s10067-016-3384-9.

14. Pepper RJ, Draibe JB, Caplin B, Fervenza FC, Hoffman GS, Kallenberg CG, et al. The association of serum calprotectin (S100A8/S100A9) levels with disease relapses in PR3-ANCA-associated vasculitis. Arthritis Rheumatol. 2016;69(1):185-93.

15. Kronbichler A, Kerschbaum J, Gründlinger G, Leierer J, Mayer G, Rudnicki M. Evaluation and validation of biomarkers in granulomatosis with polyangiitis and microscopic polyangiitis. Nephrol Dial Transplant. 2016;31(6):930-6. https://doi.org/10.1093/ndt/gfv336.

16. Sada KE, Harigai M, Amano K, Atsumi T, Fujimoto S, Yuzawa Y, Takasaki Y, Banno S, Sugihara T, Kobayashi M, Usui J, Yamagata K, Homma S, Dobashi H, Tsuboi N, Ishizu A, Sugiyama H, Okada Y, Arimura Y, Matsuo S, Makino H, for Research Committee of Intractable Vasculitis Syndrome and Research Committee of Intractable Renal Disease of the Ministry of Health, Labour, and Welfare of Japan. Comparison of severity classification in Japanese patients with antineutrophil cytoplasmic antibody-associated vasculitis in a nationwide, prospective, inception cohort study. Mod Rheumatol. 2016; 26(5):730-7. https://doi.org/10.3109/14397595.2016.1140274.

17. Ishizaki J, Takemori A, Suemori K, Matsumoto T, Akita Y, et al. Targeted proteomics reveals promising biomarkers of disease activity and organ involvement in antineutrophil cytoplasmic antibody-associated vasculitis. Arthritis Res Ther. 2017;19(1):218. https://doi.org/10.1186/s13075-017-1429-3.

18. Groh M, Pagnoux C, Baldini C, Bel E, Bottero P, Cottin V, Dalhoff K, Dunogué B, Gross W, Holle J, Humbert M, Jayne D, Jennette JC, Lazor R, Mahr A, Merkel PA, Mouthon L, Sinico RA, Specks U, Vaglio A, Wechsler ME, Cordier JF, Guillevin L. Eosinophilic granulomatosis with polyangiitis (Churg-Strauss) (EGPA) Consensus Task Force recommendations for evaluation and management. Eur J Intern Med. 2015;26(7):545-53. https://doi.org/10.1016/j. ejim.2015.04.022.

19. Puéchal X, Pagnoux C, Baron G, Quémeneur T, Néel A, Agard C, Lifermann F, Liozon E, Ruivard M, Godmer P, Limal N, Mékinian A, Papo T, Ruppert AM, Bourgarit A, Bienvenu B, Geffray L, Saraux JL, Diot E, Crestani B, Delbrel X, Sailler L, Cohen P, le Guern V, Terrier B, Groh M, le Jeunne C, Mouthon L, Ravaud P, Guillevin L, the French Vasculitis Study Group. Adding azathioprine to remission-induction glucocorticoids for eosinophilic granulomatosis with polyangiitis (Churg-Strauss), microscopic polyangiitis, or polyarteritis nodosa without poor prognosis factors: a randomized, controlled trial. Arthritis Rheumatol. 2017;69(11):2175-86. https://doi.org/10.1 002/art.40205

20. Watts R, Lane S, Hanslik T, Hauser T, Hellmich B, Koldingsnes W, Mahr A, Segelmark M, Cohen-Tervaert JW, Scott D. Development and validation of a consensus methodology for the classification of the ANCA-associated vasculitides and polyarteritis nodosa for epidemiological studies. Ann Rheum Dis. 2007;66(2):222-7. https://doi.org/10.1136/ard.2006.054593.

21. Mukhtyar C, Lee R, Brown D, Carruthers D, Dasgupta B, Dubey S, Flossmann O, Hall C, Hollywood J, Jayne D, Jones R, Lanyon P, Muir A, Scott D, Young L, Luqmani RA. Modification and validation of the Birmingham Vasculitis Activity Score (version 3). Ann Rheum Dis. 2009;68(12):1827-32. https://doi. org/10.1136/ard.2008.101279.

22. Hellmich B, Flossmann O, Gross WL, Bacon P, Cohen-Tervaert JW, Guillevin $L$, et al. EULAR recommendations for conducting clinical studies and/or clinical trials in systemic vasculitis: focus on anti-neutrophil cytoplasm antibody-associated vasculitis. Ann Rheum Dis. 2007;66(5):605-17. https:// doi.org/10.1136/ard.2006.062711.

23. Pagnoux C, Hogan SL, Chin H, Jennette JC, Falk RJ, Guillevin L, Nachman $\mathrm{PH}$. Predictors of treatment resistance and relapse in antineutrophil cytoplasmic antibody-associated small-vessel vasculitis: comparison of two independent cohorts. Arthritis Rheum. 2008;58(9):2908-18. https://doi.org/1 0.1002 /art.23800.

24. Walsh M, Flossmann O, Berden A, Westman K, Höglund P, Stegeman C, Jayne D, European Vasculitis Study Group. Risk factors for relapse of antineutrophil cytoplasmic antibody-associated vasculitis. Arthritis Rheum. 2012;64(2):542-8. https://doi.org/10.1002/art.33361.

25. Terrier B, Pagnoux C, Perrodeau É, Karras A, Khouatra C, Aumaître O, et al. Long-term efficacy of remission-maintenance regimens for ANCA-associated vasculitides. Ann Rheum Dis. 2018;77(8):1151-7. 
26. Fussner LA, Hummel AM, Schroeder DR, Silva F, Cartin-Ceba R, Snyder MR, Hoffman GS, Kallenberg CGM, Langford CA, Merkel PA, Monach PA, Seo P, Spiera RF, William St.Clair E, Tchao NK, Stone JH, Specks U, for the Rituximab in ANCA-Associated Vasculitis-Immune Tolerance Network Research Group. Factors determining the clinical utility of serial measurements of antineutrophil cytoplasmic antibodies targeting proteinase 3. Arthritis Rheumatol. 2016;68(7):1700-10. https://doi.org/10.1002/art.39637.

27. Watanabe $H$, Sada KE, Matsumoto $Y$, Harigai M, Amano K, Dobashi $H_{\text {, }}$ Fujimoto S, Usui J, Yamagata K, Atsumi T, Banno S, Sugihara T, Arimura Y, Matsuo S, Makino H, the Japan Research Committee of the Ministry of Health, Labour, and Welfare for Intractable Vasculitis, and the Research Committee of Intractable Renal Disease of the Ministry of Health, Labour, and Welfare of Japan. Association between reappearance of myeloperoxidase-antineutrophil cytoplasmic antibody and relapse in antineutrophil cytoplasmic antibody-associated vasculitis: subgroup analysis of nationwide prospective cohort studies. Arthritis Rheumatol. 2018;70(10): 1626-33. https://doi.org/10.1002/art.40538.

28. McKinney EF, Lyons PA, Carr EJ, Hollis JL, Jayne DR, Willcocks LC, et al. A CD8+ T cell transcription signature predicts prognosis in autoimmune disease. Nat Med. 2010;16(5):586-91. https://doi.org/10.1038/nm.2130.

29. Brew K, Nagase $H$. The tissue inhibitors of metalloproteinases (TIMPs): an ancient family with structural and functional diversity. Biochim Biophys Acta. 2010;1803(1):55-71. https://doi.org/10.1016/j.bbamcr.2010.01.003.

30. Ries C. Cytokine functions of TIMP-1. Cell Mol Life Sci. 2014;71(4):659-72. https://doi.org/10.1007/s00018-013-1457-3.

31. Grünwald B, Schoeps B, Krüger A. Recognizing the molecular multifunctionality and interactome of TIMP-1. Trends Cell Biol. 2019;29(1):619. https://doi.org/10.1016/j.tcb.2018.08.006

32. Kim YS, Kim SH, Kang JG, Ko JH. Expression level and glycan dynamics determine the net effects of TIMP-1 on cancer progression. BMB Rep. 2012; 45(11):623-8. https://doi.org/10.5483/BMBRep.2012.45.11.233.

33. Jackson HW, Defamie V, Waterhouse P, Khokha R. TIMPs: versatile extracellular regulators in cancer. Nat Rev Cancer. 2017;17(1):38-53. https:// doi.org/10.1038/nrc.2016.115.

34. Hoffmann U, Bertsch T, Dvortsak E, Liebetrau C, Lang S, Liebe V, et al. Matrix-metalloproteinases and their inhibitors are elevated in severe sepsis: prognostic value of TIMP-1 in severe sepsis. Scand J Infect Dis. 2006;38(10): 867-72. https://doi.org/10.1080/00365540600702058.

35. Garza MA, Wason EA, Zhang JQ. Cardiac remodeling and physical training post myocardial infarction. World J Cardiol. 2015;7(2):52-64. https://doi.org/1 0.4330/wjc.v7.i2.52.

36. Zhong C, Wang G, Xu T, Zhu Z, Guo D. Tissue inhibitor metalloproteinase-1 and clinical outcomes after acute ischemic stroke. Neurology. 2019;93(18): e1675-85. https://doi.org/10.1212/WNL.0000000000008389.

37. Sharif M, Salisbury C, Taylor DJ, Kirwan JR. Changes in biochemical markers of joint tissue metabolism in a randomized controlled trial of glucocorticoid in early rheumatoid arthritis. Arthritis Rheum. 1998;41(7):1203-9. https://doi. org/10.1002/1529-0131(199807)41:7<1203::AID-ART9>3.0.CO;2-2.

38. Ribbens C, Martin y Porras M, Franchimont N, Kaiser MJ, Jaspar JM, Damas P, et al. Increased matrix metalloproteinase-3 serum levels in rheumatic diseases: relationship with synovitis and steroid treatment. Ann Rheum Dis. 2002;61(2):161-6. https://doi.org/10.1136/ard.61.2.161.

39. Hattori $Y$, Kida D, Kaneko A. Steroid therapy and renal dysfunction are independently associated with serum levels of matrix metalloproteinase-3 in patients with rheumatoid arthritis. Mod Rheumatol. 2018;28(2):242-8. https://doi.org/10.1080/14397595.2017.1354431.

40. Rodriguez-Pla A, Warner RL, Cuthbertson D, Carette S, Khalidi NA, Koening CL, Langford CA, McAlear C, Moreland LW, Pagnoux C, Seo P, Specks U, Sreih AG, Ytterberg SR, Johnson KJ, Merkel PA, Monach PA, Vasculitis Clinical Research Consortium. Evaluation of potential serum biomarkers of disease activity in diverse forms of vasculitis. J Rheumatol. 2020;47(7):1001-10. https://doi.org/10.3899/jrheum.190093.

41. Fujimoto S, Watts RA, Kobayashi S, Suzuki K, Jayne DR, Scott DG, et al. Comparison of the epidemiology of anti-neutrophil cytoplasmic antibodyassociated vasculitis between Japan and the U.K. Rheumatology (Oxford). 2011;50(10):1916-20.

42. Sada KE, Yamamura M, Harigai M, Fujii T, Dobashi H, Takasaki Y, Ito S, Yamada H, Wada T, Hirahashi J, Arimura Y, Makino H, the Research Committee on Intractable Vasculitides, the Ministry of Health, Labour and Welfare of Japan. Classification and characteristics of Japanese patients with antineutrophil cytoplasmic antibody-associated vasculitis in a nationwide, prospective, inception cohort study. Arthritis Res Ther. 2014;16(2):R101. https://doi.org/10.1186/ar4550.

\section{Publisher's Note}

Springer Nature remains neutral with regard to jurisdictional claims in published maps and institutional affiliations.
Ready to submit your research? Choose BMC and benefit from:

- fast, convenient online submission

- thorough peer review by experienced researchers in your field

- rapid publication on acceptance

- support for research data, including large and complex data types

- gold Open Access which fosters wider collaboration and increased citations

- maximum visibility for your research: over $100 \mathrm{M}$ website views per year

At BMC, research is always in progress.

Learn more biomedcentral.com/submissions 